\title{
Características morfológicas de la gástrula en Ceratophrys stolzmanni (Anura: Ceratophryidae).
}

\author{
Juan Diego Santillana Ortiz y Eugenia M. del Pino \\ Pontificia Universidad Católica del Ecuador, Escuela de Ciencias Biológicas, \\ Laboratorio de Biología del Desarrollo, 12 de Octubre 1076 y Roca, \\ Quito, Ecuador \\ 'edelpino@puce.edu.ec
}

RESUMEN: Se estudió la morfología de la gástrula y néurula en embriones de Ceratophrys stolzmanni (el sapo bocón de la costa). Los huevos, cuyo diámetro al comienzo de la gastrulación es de 2,2 $\mathrm{mm}$, se desarrollan rápidamente. El proceso de gastrulación dura aproximadamente cinco horas. Los embriones fueron fijados y analizados en montaje entero, bisecciones y secciones de vibrátomo. Se encontró que los huevos tienen pigmento oscuro al igual que en Xenopus laevis, pero tienen un tamaño mayor. La morfología de la gástrula de C. stolzmanni es similar a la descrita para Ceratophrys ornata (el sapo cornudo argentino) por otros autores. Los estadios de gástrula tardía y néurula temprana, estudiados mediante secciones con tinción fluorescente para núcleos celulares, revelan ausencia de endodermo que recubra al notocordio y a los somitas en la parte dorsal posterior del embrión. Esta región se denomina GRP (Gastrocoel roof plate, por sus siglas en inglés) y tiene importancia en la determinación del eje izquierdo-derecho en anfibios. En este estudio se caracterizó el GRP de C. stolzmanni al nivel morfológico.

PALABRAS CLAVE: Ceratophrys ornata, Ceratophrys stolzmanni, Gastrulación, GRP, Xenopus laevis.

ABSTRACT: The gastrula morphology of Ceratophrys stolzmanni (the Pac-man frog) was studied. Its eggs, whose diameter at the beginning of the gastrulation process is 2.2 $\mathrm{mm}$ in diameter, develop rapidly. The gastrulation process requires five hours approximately. The embryos were fixed and analyzed in whole-mount, in bisections, and vibratome sections. The eggs of C. stolzmanni were pigmented, as in Xenopus laevis, but their size was bigger. The gastrula morphology of $C$. stolzmanni is similar to the one described for Ceratophrys ornata (the argentine horned-frog) by other authors. The late gastrula and early neurula stages, studied with vibratome sections stained for cell nuclei, revealed lack of endoderm covering both the posterior notochord and the somites found on this region. This region is called the GRP (Gastrocoel roof plate) and it plays a major role in the development of the left-right axis in amphibians. In this work the GRP of $C$. stolzmanni was characterized at the morphological level.

KEYWORDS: Ceratophrys ornata, Ceratophrys stolzmanni, Gastrulation, GRP, Xenopus laevis. 


\section{INTRODUCCIÓN}

Las diferencias en el desarrollo temprano de las ranas, tales como el tamaño de los embriones, el proceso de gastrulación y la velocidad del desarrollo, son aspectos necesarios de estudio para la comprensión del desarrollo embrionario. En particular, el proceso de gastrulación en diversas especies de anfibios muestra la existencia de tres patrones distintos. Estos patrones se relacionan con la velocidad del desarrollo de las especies. Por un lado, las ranas de desarrollo rápido, como Xenopus laevis (Daudin, 1802), extienden el arquenterón y alargan el notocordio durante la gastrulación; mientras que ranas de desarrollo lento, como Gastrotheca riobambae (Fowler, 1913), posponen el alargamiento del notocordio a la post gástrula (1). Esto sugiere que el proceso de gastrulación es modular, es decir que la expansión del arquenterón y el cierre del blastoporo son procesos regulados de forma independiente y a distinto tiempo (1). Los estudios comparativos entre ranas que difieren en sus modos de reproducción, tales como Epipedobates machalilla (Coloma, 1995) y Epipedobates tricolor (Boulenger, 1899b) (reproducción terrestre), G. riobambae (incubación en una bolsa materna) y la rana acuática $X$. laevis sugieren que las diferencias en el desarrollo embrionario temprano están relacionadas con distintas estrategias reproductivas (1). Es importante entonces ampliar los estudios comparativos y describir los procesos de desarrollo para especies con diversas estrategias reproductivas.
Una rana lejanamente relacionada con las anteriores especies es Ceratophrys stolzmanni (Steindachner, 1882) (el sapo bocón de la costa). Esta rana vive bajo el suelo en ambientes xéricos del sur del Ecuador y norte del Perú y deposita sus huevos en charcas temporales cuando comienza la estación lluviosa. Ésta es una especie interesante para ser estudiada debido a su diferente estrategia reproductiva. Si bien el desarrollo embrionario de $C$. stolzmanni no se había estudiado, sí se conocen aspectos del desarrollo en una especie cercana a ésta: la rana cornuda argentina Ceratophrys ornata. El anuro $C$. ornata tiene un modo de vida terrestre pero deposita sus huevos, de 1,5 - 2,0 $\mathrm{mm}$ de diámetro, en el agua. Su desarrollo desde la fertilización hasta convertirse en renacuajo es sumamente rápido, entre 24-48 horas. De su desarrollo temprano se conoce que presenta mesodermo superficial en el techo del gastrocele el mismo que ingresa a las capas mesodermales profundas durante la neurulación (2).

Este mesodermo superficial forma una estructura en el techo del arquenterón que está expuesta a la cavidad del gastrocele (3). En los anfibios a esta estructura se la conoce como placa del techo del gastrocele, GRP, gastrocoel roof plate, por sus siglas en inglés (3). El GRP es una región con células ciliadas que promueven un flujo de sustancias no determinadas en sentido izquierdo. Este flujo es el evento que permite el establecimiento de la cascada de la señal molecular Nodal para la especificación asimétrica del cuerpo. El GRP está bordeado por las crestas laterales endodermales (4) las que gradualmente lo cubren (1). El GRP es análogo a estructuras similares encontradas en otros vertebrados (3). 
En $X$. laevis y Xenopus tropicalis (Wagler 1827) el GRP mide aproximadamente $260 \mu \mathrm{m}$ y $150 \mu \mathrm{m}$ de largo respectivamente. Los cilios tienen una longitud promedio de $5 \mu \mathrm{m}$ (5). Por el significado del GRP en el establecimiento del eje izquierdo-derecho es importante demostrar su presencia en embriones de ranas con modos divergentes de gastrulación como es C. stolzmanni.

\section{MATERIALES Y MÉTODOS}

Los embriones con los que se realizó este estudio fueron donados por el Laboratorio de Herpetología de la Pontificia Universidad Católica del Ecuador (PUCE). Estos embriones provinieron de dos posturas: La primera de ranas colectadas en la provincia de El Oro, Ecuador; y la segunda de ranas criadas en cautiverio dentro del programa de investigación "Balsa de los sapos".

Los embriones se cultivaron en recipientes de plástico. La temperatura ambiente fue de $30{ }^{\circ} \mathrm{C}$ y $26{ }^{\circ} \mathrm{C}$ la del agua. Los acuarios fueron artificialmente oxigenados.

Se estudió la morfología externa de la gástrula y néurula mediante montajes enteros de embriones fijados en el fijativo de Smith. La estructura interna de los embriones fue descrita mediante bisecciones y secciones. Para realizar las secciones los embriones fueron primero embebidos en gelatina, luego montados en cubos de agarosa y, mediante el uso del vibrátomo, se obtuvieron secciones de $40-50 \mu \mathrm{m}$ de grosor. Algunas de estas secciones fueron también estudiadas usando la metodología de tinción fluorescente para núcleos celulares (tinción Hoechst 33258). Se documentaron las observaciones mediante microfotografías usando una cámara digital acoplada a un estéreomicroscopio o a un microscopio de fluorescencia. Todas estas técnicas se enmarcan en metodologías estándar del Laboratorio de Biología del Desarrollo de la PUCE. Los estadios de los embriones se determinaron de acuerdo a la tabla general para el desarrollo de anuros (6) y para C. ornata (2).

\section{RESULTADOS}

Morfología de la gástrula de $C$. stolzmanni.- El proceso de gastrulación duró aproximadamente 5 horas. La gástrula temprana (estadio 10,5;2,2 mm de diámetro) se caracterizó por la formación del labio dorsal del blastoporo, en forma de hendidura, en la región sub-ecuatorial del embrión. Se detectaron células en forma de botella en dicha hendidura. Se observó pigmento ocre oscuro en el polo animal del embrión así como un pigmento blanco claro en el polo vegetal.

La gástrula media (estadio 11) se caracterizó por la extensión lateral y ventral del labio del blastoporo, el mismo que tuvo forma de herradura (Fig. 1A). Internamente el blastocele ocupó la mayor parte de la región animal. El arquenterón inició su formación pero no se expandió. 

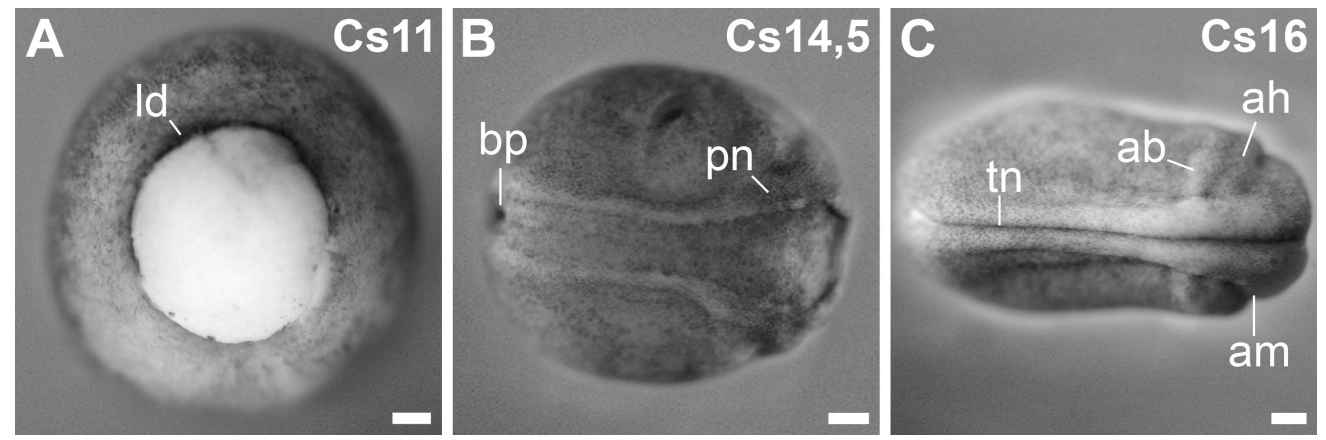

Fig. 1. Desarrollo temprano de C. stolzmanni: gástrula y néurula. (A) Gástrula media. (B) Néurula media. (C) Estadio de cerramiento del tubo neural. Abreviaturas: lb, labio del blastoporo; pn, pliegues neurales; bp, blastoporo; tb, tubo neural; ab, arco branquial; ah, arco hioideo; am, arco mandibular. Todas las barras corresponden a $250 \mu \mathrm{m}$.

La gástrula tardía (estadio 12) externamente mostró una disminución gradual del diámetro del tapón de yema. Internamente los movimientos de convergencia y extensión dorsales permitieron el alargamiento y expansión del arquenterón. En el estadio 12,5 se observó que el tapón de yema continuaba su gradual reducción. En una sección sagital de un embrión de este estadio, teñido para núcleos celulares, se observaron el labio dorsal y ventral del blastoporo así como el cleft de Brachet que separa el ectodermo del endomesodermo.

Morfología de la néurula de $\boldsymbol{C}$. stolzmanni.- Los embriones en el estadio 13 muestran una reducción del tapón de yema. En el estadio temprano de formación de pliegues neurales (estadio 14) se observó alargamiento del embrión (2,3 $\mathrm{mm}$ de largo) y la formación de pliegues neurales. En una sección horizontal para este mismo estadio, al nivel del tapón de yema y teñida para núcleos celulares, se observó que el notocordio está expuesto en el techo del arquenterón. En el estadio 14,5 $(2,4 \mathrm{~mm}$ de largo $)$ los pliegues neurales fueron más prominentes (Fig. 1B). Durante el estadio medio de pliegues neurales (estadio 15; 2,7 $\mathrm{mm}$ de largo) los pliegues neurales se acercaron pero el tubo neural permaneció abierto. En el estadio de cerramiento del tubo neural (estadio 16), el tubo neural se cerró pero permaneció abierto en la región rostral. En la misma región se observaron los arcos branquiales: mandibular, hioideo y branquial (Fig. 1C).

La eclosión ocurrió en el segundo día. Este tiempo de desarrollo es comparable con X. laevis (7).

Morfología del techo del arquenterón en $\boldsymbol{C}$. stolzmanni.- El techo del arquenterón se estudió en bisecciones de embriones de estadios 13-15 con el objeto de determinar sus características morfológicas. En la región caudal del techo del arquenterón de un embrión de estadio 13 (Fig. 2A) se observó un área pigmentada triangular, el GRP (Fig. 2B). 

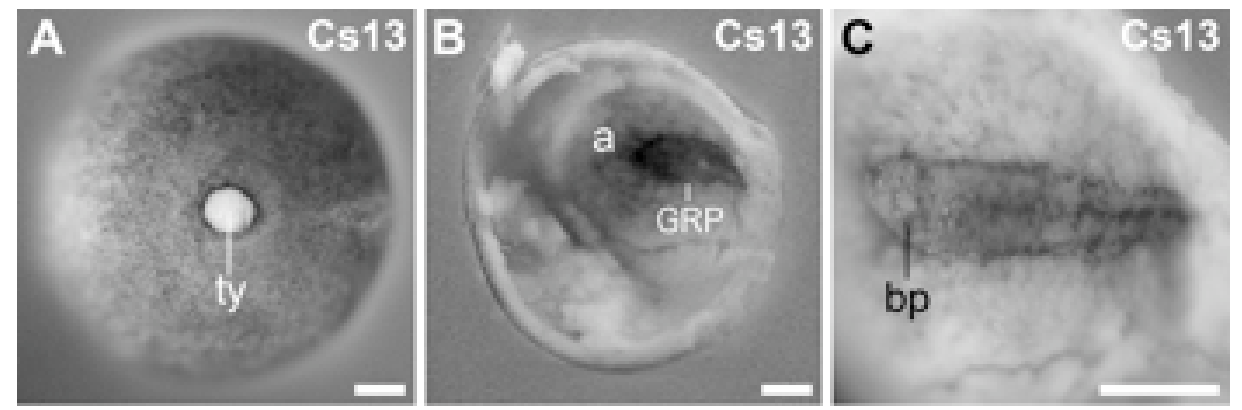

Fig. 2. Techo del arquenterón de C. stolzmanni. (A) Gástrula temprana. (B) Bisección de gástrula temprana. (C) GRP. Abreviaturas: ty, tapón de yema; a, arquenterón; GRP, placa del techo del gastrocele; bp, blastoporo. Todas las barras corresponden a $250 \mu \mathrm{m}$.

Esta estructura se observó como una región con tres bandas más oscuras localizadas en la región central y lateral. Las bandas del GRP convergieron en la parte media anterior (Fig. 2C).

En secciones transversales de estadios 13 y 14, teñidas para núcleos celulares y efectuadas a diferentes niveles del eje antero-posterior, se evidenció que el notocordio y los somitas estaban recubiertos por endodermo en la parte anterior y descubiertos en la región posterior. Es decir, en estos estadios se encontró que el mesodermo está expuesto en la parte posterior del techo del arquenterón correspondiente a la región del GRP. Se encontró también que el embrión de C. stolzmanni presenta un collar circumblastoporal prominente incluso en embriones que tienen tapón de yema y muestran al GRP. En secciones del estadio 15 el notocordio y somitas estuvieron recubiertos por endodermo.

\section{DISCUSIÓN}

En este estudio se demostró que $C$. stolzmanni es una especie que tiene desar- rollo rápido, comparable al de la rana acuática $X$. laevis y diferente al de las especies de reproducción terrestre $E$. machalilla, E. tricolor (1) y G. riobambae (9). Por otro lado el tamaño del huevo es mayor que en $X$. laevis $1,3 \mathrm{~mm}$ (7) y 2,2 $\mathrm{mm}$ de diámetro respectivamente, y es comparable al tamaño de los huevos de $E$. tricolor de $2 \mathrm{~mm}$ de diámetro (1). La pigmentación oscura del polo animal es comparable a $X$. laevis (7). El proceso de gastrulación es similar al de $C$. ornata ya que en ambas especies el labio dorsal del blastoporo se forma más cerca del ecuador que en comparación con X. laevis (2) (7). En la morfología externa de la néurula no se observaron diferencias significativas con el patrón de otros anuros (7) (8) (10).

El análisis de la morfología del techo del arquenterón de C. stolzmanni sugiere la presencia del GRP. Al igual que en $X$. laevis esta estructura fue visible entre la gástrula tardía y néurula temprana (7), aunque de mayor tamaño y más visible. Además un estudio en progreso ha revelado la presencia de cilios en esta estructura (Sáenz-Ponce, et al. comunicación personal). La comparación del techo del 
arquenterón entre $C$. ornata y $C$. stolzmanni revela gran similitud. En ambas especies, en embriones del estadio 13, la región anterior-media del techo del arquenterón está recubierta por endodermo, mientras que la parte posterior está descubierta. En la figura 3 se esquematiza la ausencia de endodermo que recubra al notocordio y somitas en C. ornata (Fig.

\section{C. ornata}

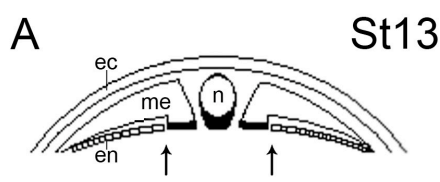

B
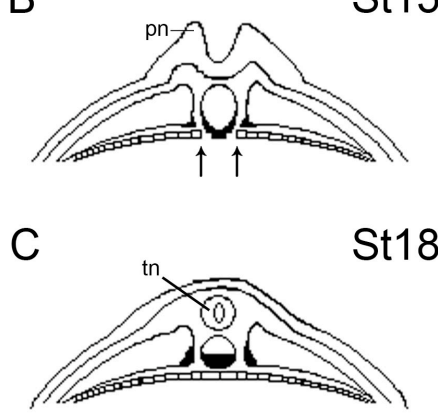

notocordio se encuentra aún expuesto (Fig. 3B). Tanto los somitas como el notocordio han sido recubiertos totalmente por endodermo en embriones de estadio 18 (Fig. 3C) de acuerdo con (2). En embriones del estadio 13 de $C$. stolzmanni nuestras observaciones demostraron que el notocordio y los somitas se encuentran expuestos en la

\section{C. stolzmanni}

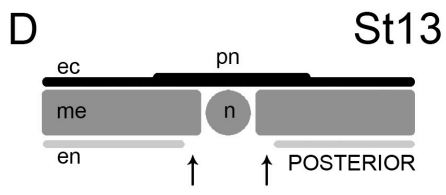

$E$

St13

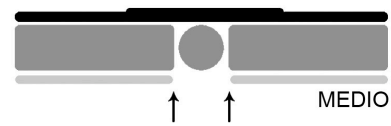

F

St13

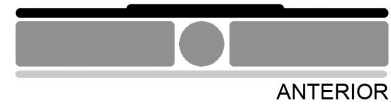

Fig. 3. Esquema comparativo del techo del arquenterón entre C. ornata y C. stolzmanni. C. ornata: (A) Néurula temprana, (B) Néurula tardía, y (C) Estadio tail bud; C. stolzmanni: (St. 13, néurula temprana): (D) Región posterior, (E) Región media, y (F) Región anterior. Las flechas señalan el límite de la región mesodérmica expuesta en el techo del arquenterón, el GRP. Abreviaturas: ec, ectodermo; me, mesodermo, en, endodermo; n, notocordio; pn, pliegues neurales; tn, tubo neural. Dibujos de C. ornata modificados de (2).

3 A-C) y C. stolzmanni (Fig. 3 D-F). En la región media del embrión de estadio 13 de C. ornata el notocordio y los somitas se encuentran expuestos en el techo del arquenterón (Fig. 3A). En embriones de estadio 15 las crestas endodermales laterales han recubierto los somitas, pero el región media-posterior (Fig. 3D-F). El color del GRP en C. stolzmanni posiblemente se deba a que durante los movimientos morfogenéticos de la gastrulación el mesodermo superficial, que tiene pigmento oscuro, se ha internalizado y ocupa la región dorsal del techo del 
arquenterón. La acumulación de pigmento puede ser una consecuencia de la constricción apical en las células del GRP como se observa en C. ornata (2).

Este estudio señala la importancia de determinar la modularidad del GRP en especies de ranas con distintas estrategias reproductivas para comprender mejor el establecimiento del eje izquierdo-derecho.

\section{AGRADECIMIENTOS}

Agradecemos a los Drs. L.A. Coloma y D. Almeida-Reinoso así como a los otros miembros del Laboratorio de Herpetología de la PUCE por la donación de posturas de C. stolzmanni. La reproducción de esta rana recibió apoyo económico del programa de investigación "Balsa de los sapos". A los colaboradores del Laboratorio de Biología del Desarrollo de la misma universidad se agradece por sus comentarios y soporte experimental. Este trabajo recibió el apoyo de la beca de investigación de la PUCE-2008 al proyecto Expresión génica en el desarrollo de ranas ecuatorianas.

\section{BIBLIOGRAFÍA}

1.- DEL PINO, E.M., VENEGAS-FERRÍN, M., ROMERO-CARVAJAL, A., MONTENEGRO-LARREA, P., SÁENZPONCE, N., MOYA, I.M., ALARCÓN, I., SUDOU, N., YAMAMOTO, S. \& TAIRA, M. 2007. A comparative analysis of frog early development. Proceedings of the national academy of sciences, 104: 11882-
11888.

2.- PURCELL, S.M. \& KELLER, R. 1993. A different type of amphibian mesoderm morphogenesis in Ceratophrys ornata. Development, 117: 307-317.

3.- BLUM, M., WEBER, T., BEYER, T. y VICK, P. 2008. Evolution of leftward flow. Seminars in cell and developmental biology. [Epub ahead of print - PMID: 19056505 - PubMed - as supplied by publisher].

4.- KELLER, R. \& SHOOK, D. 2004. Gastrulation in amphibians. En: STERN, C. ed. Gastrulation: From cells to embryo. 171203. Cold spring harbor laboratory press. New York. E.E.U.U.

5.- SCHWEICKERT, A., WEBER, T., BEYER, T. VICK, P., BOGUSC, S., FEISTEL, K. \& BLUM, M. 2007. Cilia-driven leftward flow determines laterality in Xenopus. Current biology, 17: 60-66.

6.- GOSNER, K.L. 1960. A simplified table for staging anuran embryos and larvae with notes on identification. Herpetologica, 16: 183-190.

7.- NIEUWKOOP, P.D. \& FABER, J. 1994. Normal table of Xenopus laevis (Daudin). Garland publishing. London. 252pp.

8.- DEL PINO, E.M., ÁVILA, M.E., PÉREZ, O.D., BENÍTEZ, M.S., ALARCÓN, I., NOBOA, V. \& MOYA, I. 2004. Development of the dendrobatid frog Colostethus machalilla. Developmental biology, 48: 663-670.

9.- MOYA, I.M., ALARCÓN, I. \& DEL PINO, E.M. 2007. Gastrulation of Gastrotheca riobambae in comparison with other frogs. Developmental biology, 304: 467-478.

10.- DUELLMAN, W.E. \& TRUEB, L. 1994. Biology of amphibians. The John Hopkins University Press. Baltimore, USA. 